\title{
Research on the Association of Southeast Asian Nations Based on Social Network Analysis
}

\author{
Chu Qiu \\ Logistics University of People's Armed Police Force \\ Tianjin, P.R. China \\ autumnchq@gmail.com
}

\begin{abstract}
The Association of Southeast Asian Nations (ASEAN) is a burgeoning regional international organization. It has played important role in many respects, such as political and economic. Researches which focused on this organization have gained many attentions for a long time. The Social Network Analysis (SNA) is considered to be an effective method in the study of relationships. Our manuscript is mainly based on the economic and trade data among the members of the ASEAN in 2013. With the help of the Organizational Risk Analyzer (ORA), we finished quantitative calculation of network parameters. All the results showed that the Singapore, Indonesia, and Malaysia have occupied the central positions. Due to the limitation of the raw data, the importance of Malaysia and Indonesia has not been fully reflected. Based on the results, we suggest that governments should pay more attention to handle the regional affairs of neighboring countries in order to enhance their influence in the ASEAN.
\end{abstract}

Keywords- Social Networks Analysis; Association of Southeast Asian Nations; International Relation; Organizational Risk Analyzer.

\section{INTRODUCTION}

The Association of Southeast Asian Nations (ASEAN) was formed by its initial founders, Indonesia, Philippines, Thailand, Singapore, and Malaysia on August 8, 1967 [1]. After their members including the Brunei, Cambodia, Vietnam, Laos, and Myanmar (Burma), it has become a very famous political and economic organization of ten Southeast Asian countries [2]. In the recent years, the ASEAN has played an important role in promoting economic growth, accelerating social progress, and maintaining the sociocultural stability [3]. And its cooperative scope now has extended to protection of the regional peace and stability, and opportunities to resolve differences peacefully for its members [4].

ASEAN organizational structure contains three pillars, the Socio-Cultural Community (ASCC), the Economic Community (AEC), and the Political-Security Community (APSC) [5]. It now covers $10 \%$ land area of the Asian continent, which is about 4.4 million square kilometers. And the territorial waters cover about 3 times larger than its land area. The population of its members is about 625 million people, which is $8.8 \%$ of the world's population [6]. ASEAN combined nominal GDP would rank as the 7th largest economy in the world at the end of 2015, which is now expected to grow to more than 2.6 trillion US dollars [7].

All Inter-government Organizations (IGOs) as the ASEAN can be converted to a network, and its network architecture will also affect behaviors of the members. At present, most related works concerning the ASEAN were focused on the economic cooperation [8]. Now, the primary goal of ASEAN is to seek its economic integration by establishing a common market by the end of 2015. The Social Network Analysis (SNA) has become a hot qualitative method in the international relations, since the famous book, "Networks of Nations: The Evolution, Structure, and Impact of International Networks, 1816-2001" was once published by Zeev Maoz [9]. Our research is mainly focus on exploring the architecture of ASEAN from the Social Network perspective.

\section{MEASUREMENT OF THE SOCIAL NETWORK ANALYSIS}

The SNA uses network perspective to understand and study many kinds of international organizations. It often regards relationships as a network, which contains many individuals and communications as the nodes and edges [10]. Meanwhile, networks has many metrics, and their values are calculated as magnitude and frequency of interaction among the nodes. The most popular tool in the SNA is Organizational Risk Analyzer (ORA), which was developed by the Center for Computational Analysis of Social and Organizational Systems (CASOS) [11]. At first, we would give a brief introduction about the measures in the Social Network Analysis.

\section{A. Network Density}

Density is an important measure to discribe the connecting condition of a network, as it always composed of nodes and connections. The real situation of edges represent as potential or exist. The formula in directed or undirected graph might be different, and we could caculate them as follows(1) (2) [12].

$$
\begin{aligned}
& D_{U}=\frac{2 l}{n(n-1)} \\
& D_{D}=\frac{l}{n(n-1)}
\end{aligned}
$$




\section{B. Total Degree Centrality}

The Total Degree Centrality is considered to one of the key measures in social network analysis. Degree Centrality always tells us numbers of direct connections of a node which existed in a network; and the higher score of such node may be more likely to receive some potentially information flows through the organization, and we could caculate it as follows (3) [13].

$$
\text { Degree }=\frac{1}{2(n-1)} \sum_{\substack{i=1 \\ i \neq 1 \\ i \neq j}}^{n} \sum_{\substack{i=1 \\ i \neq}}^{n}(i, j)
$$

\section{Bonacich Power Centrality}

The Bonacich Power is an more thorough measurement. It used to compute the importance of node in the whole network. And this centrality of each node also based on the influence of its neighbors. Specifically, let $A$ as an adjacency matrix of the network. And then Bonacich Power Centrality for the network can be caculated as the following equations (4) [14]:

$$
(I-\beta A)^{-1} c=A e
$$

Where $I$ is the identity matrix, and $e$ is a vector of ones. We should note $\beta$ is 0 , then $c$ is simply equal to the degree of each node. The values of $c$ are not normalized.

\section{Closeness Centrality}

The Closeness Centrality measures path length from one node to another in a network. It tells us which one is central to this organization. Moreover, it means high scoring individuals in Closeness will have the shortest paths in the network. That is to say, such individuals could monitor the information flow better than the others in the whole organization (5) [15].

$$
C_{R P}=\frac{\sum_{j=1}^{n} d_{i j}}{n-1}
$$

The Inverse Closeness is defined as the sum of the inverse distances among an node to all the others. And this measure is defined for directed networks (6) [16].

$$
C_{R P i}=\sum_{i \in V} \frac{1}{d_{G}(v, i)}
$$

\section{E. Graph Centralization}

According to the historical experience, the Point Centrality and Graph Centralization are always not the same to the others. The Graph Centralization take greater emphasis on the overall conditions of the network. And this conception has a variety of meanings in many fields. The formula is as following(7) (8) [17].

$$
\begin{gathered}
C=\frac{\sum_{i=1}^{n}\left(C_{\max }-C_{i}\right)}{\max \left[\sum_{i=1}^{n}\left(C_{\max }-C_{i}\right)\right]} \\
C_{A D}=\frac{\sum_{i=1}^{n}\left(C_{A D \max }-C_{A D i}\right)}{\max \left[\sum_{i=1}^{n}\left(C_{A D \max }-C_{A D i}\right)\right]}
\end{gathered}
$$

\section{RESULTS BASED ON THE ORGANIZATIONAL RISK ANALYZER}

In order to verify the approaches above, we gathered some data about economic exchanges from UN Comtrade Statistics Database as the basis of our calculations [18]. The association matrix are all based on the trade volume among the ASEAN in 2013. And Centrality analysis is used to find such prominent countries which have a significant impact of entire organization. According to the theories of the SNA, these countries may have more influence on final decision making of the network, and they may reap some more additional benefits just because of their positions. For example, some advantages of opportunities, influence, information, and so on [19].

TABLE I. THE ASSOCIATION MATRIX OF TRADE FLOW OF THE ASEAN IN 2013

\begin{tabular}{|c|c|c|c|c|c|c|c|c|c|c|}
\hline Member & IDN & MYS & SGP & THA & PHL & BRN & MMR & KHM & LAO & VNM \\
\hline IDN & - & 106666095 & 166862386 & 60618700 & 38169626 & 1226959 & 5563748 & 3124611 & 58463 & 24008798 \\
\hline MYS & 133225330 & - & 317788659 & 126609840 & 29625301 & 8210383 & 7169507 & 2354355 & 228682 & 42272910 \\
\hline SGP & 255815203 & 254320677 & - & 151723668 & 66955389 & 22057186 & 22454127 & 11062232 & 263349 & 108699238 \\
\hline THA & 107030741 & 122620037 & 92744775 & - & 35643861 & 1662034 & 37903249 & 42577589 & 37591491 & 71860947 \\
\hline PHL & 7773839 & 15054671 & 50875340 & 19355656 & - & 85132 & 226816 & 96484 & 7976 & 5239326 \\
\hline BRN & 6453923 & 3290638 & 553274 & 5465477 & 11686 & - & 356 & 11 & 3 & 6023037 \\
\hline MMR & 731514 & 1981614 & 1792308 & 40329259 & 247652 & 8568 & - & 2626 & 0 & 1235149 \\
\hline KHM & 178447 & 1946614 & 1815815 & 3552724 & 121847 & 475 & 6754 & - & 5822 & 5036491 \\
\hline LAO & 75451 & 12588 & 57627 & 13600451 & 124 & 1 & 0 & 53682 & - & 6687243 \\
\hline VNM & 27226375 & 60356976 & 30573884 & 32689552 & 8706644 & 103573 & 2297469 & 29339968 & 4231867 & - \\
\hline
\end{tabular}

a. The measurement unit is thousand USD. 
At first, we constructed the association matrix as Table 1. All the raw experimental data are based on the trade volume of ASEAN member states in 2013. And then some caculations are finished automatically by Organizational Risk Analyzer. And the results are shown from the Table 2 to the Table 5. The first three tables are about the Centrality of the network, which we present above. The lastest one is about the measurement of the network level, which we called the Graph Centralization. Finally, a stacked bar chart of the statistical analysis of the ASEAN was shown in Figure 1. We can recognize the central position of the Indonesia, Singapore and Malaysia easilly.

TABLE II.

Centrality ANALYsis OF THE NeTwork (1)

\begin{tabular}{|c|c|c|c|c|}
\hline \multirow{2}{*}{ Member } & \multicolumn{4}{|c|}{ Measurement } \\
\cline { 2 - 5 } & Bonacich Power & Eigenvector & Total & Authority \\
\hline BRN & 21798403 & 0.020 & 0.008 & 0.077 \\
\hline IDN & 406299361 & 0.524 & 0.142 & 0.736 \\
\hline KHM & 12664989 & 0.012 & 0.004 & 0.108 \\
\hline LAO & 20487169 & 0.016 & 0.007 & 0.053 \\
\hline MMR & 46328688 & 0.046 & 0.016 & 0.130 \\
\hline MYS & 667484938 & 0.813 & 0.233 & 0.671 \\
\hline PHL & 98715249 & 0.137 & 0.035 & 0.315 \\
\hline SGP & 893351117 & 0.867 & 0.312 & 0.557 \\
\hline THA & 549634703 & 0.353 & 0.192 & 0.600 \\
\hline VNM & 195526308 & 0.147 & 0.068 & 0.449 \\
\hline \multicolumn{5}{|c|}{ b. All the network parameters are dimensionless after standardization. }
\end{tabular}

TABLE III.

CENTRAlity ANALYsis OF THE NeTWORK (2)

\begin{tabular}{|c|c|c|c|c|}
\hline \multirow{2}{*}{ Member } & \multicolumn{4}{|c|}{ Measurement } \\
\cline { 2 - 5 } & Capability & Betweenness & Closeness & Burt \\
\hline BRN & 0.993 & 0.667 & 0.072 & 0.832 \\
\hline IDN & 0.993 & 0.000 & 0.000 & 0.797 \\
\hline KHM & 0.993 & 0.194 & 0.001 & 0.747 \\
\hline LAO & 0.980 & 0.722 & 0.124 & 0.958 \\
\hline MMR & 0.980 & 0.111 & 0.000 & 0.856 \\
\hline
\end{tabular}

\begin{tabular}{|c|c|c|c|c|}
\hline MYS & 0.993 & 0.000 & 0.000 & 0.709 \\
\hline PHL & 0.993 & 0.000 & 0.000 & 0.835 \\
\hline SGP & 0.993 & 0.000 & 0.000 & 0.568 \\
\hline THA & 0.993 & 0.000 & 0.000 & 0.592 \\
\hline VNM & 0.993 & 0.000 & 0.000 & 0.720 \\
\hline \multicolumn{5}{|c|}{${ }^{\text {c. }}$ All the network parameters are dimensionless after standardization. }
\end{tabular}

TABLE IV. CENTRALITY ANALYSIS OF THE NETWORK(3)

\begin{tabular}{|c|c|c|c|c|}
\hline \multirow{2}{*}{ Member } & \multicolumn{4}{|c|}{ Measurement } \\
\cline { 2 - 5 } & Distinctiveness & Expertise & Similarity & Hub \\
\hline BRN & 0.222 & 1.000 & 0.778 & 0.036 \\
\hline IDN & 0.222 & 1.000 & 0.778 & 0.606 \\
\hline KHM & 0.222 & 1.000 & 0.778 & 0.019 \\
\hline LAO & 0.267 & 0.889 & 0.733 & 0.027 \\
\hline MMR & 0.267 & 0.889 & 0.733 & 0.071 \\
\hline MYS & 0.222 & 1.000 & 0.778 & 0.723 \\
\hline PHL & 0.222 & 1.000 & 0.778 & 0.200 \\
\hline SGP & 0.222 & 1.000 & 0.778 & 0.735 \\
\hline THA & 0.222 & 1.000 & 0.778 & 0.654 \\
\hline VNM & 0.222 & 1.000 & 0.778 & 0.307 \\
\hline
\end{tabular}

TABLE V. The MEASUREMENT OF NETWORK-LEVEL

\begin{tabular}{|c|c|c|c|}
\hline Measure & Value & Measure & Value \\
\hline Density & 0.978 & Interdependence & 0.023 \\
\hline Density(Weighted) & 0.102 & Efficiency (Global) & 0.020 \\
\hline Transitivity & 0.977 & Efficiency (Local) & 0.022 \\
\hline Efficiency & 0.028 & Column Degree & 0.263 \\
\hline Diffusion & 0.998 & Shared Situation & 0.100 \\
\hline
\end{tabular}




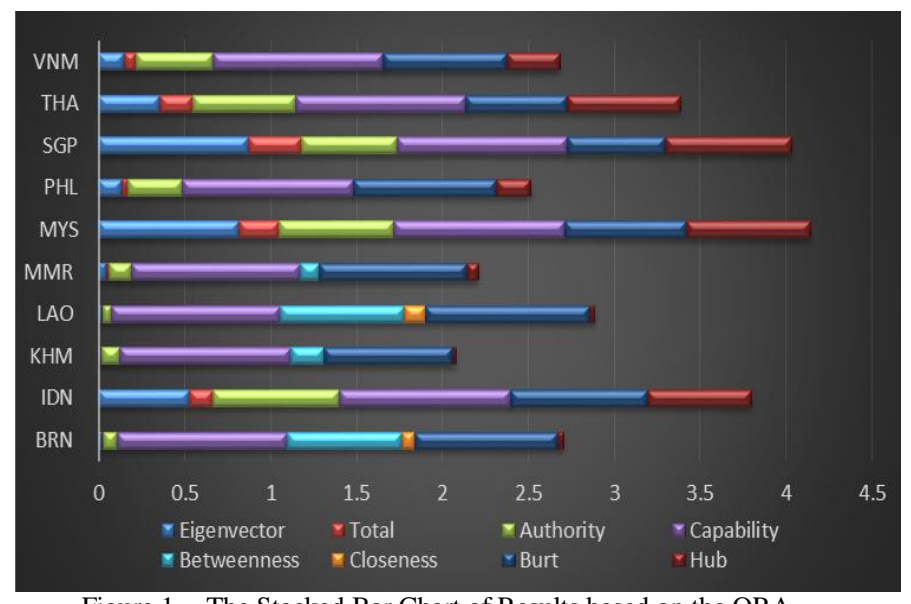

The results in the tables significantly shows that Indonesia, Singapore, and Malaysia have completely occupied the center position of the ASEAN, especially in the Bonacich Power, the Eigenvector Centrality, Authority Centrality and some other associated measurements. The other countries are all belong to an affiliate location. And this is generally the same as the real situation among countries. Laos plays an most important role in Betweenness Centrality, althought it was not a major role in this region. We can have an intuitive understanding of this situation in the Figure 2.

Figure 1. The Stacked Bar Chart of Results based on the ORA

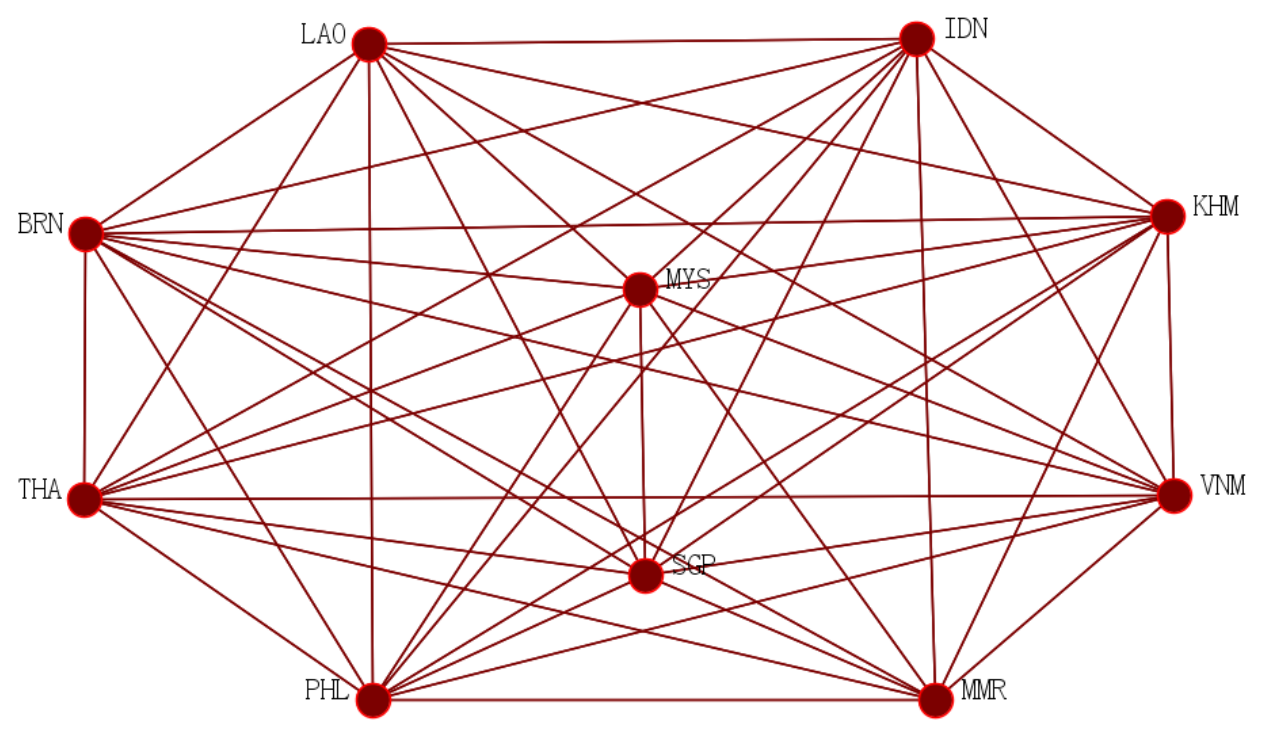

Figure 2. Contour Chart of the Results based on the ORA

As most of the data were based on trade volume, Singapore takes a relatively central role in the ASEAN. Conversely, the leading position of Malaysia and Indonesia may become more prominent if our data was on the basis of political connections. Compared to the other countries, the Indonesia has the highest Authority Centrality in the ASEAN. In recent years, the role of Singapore is much stronger on economic ties with the South-Asian countries, and it is very important in regional affairs too. And other countries are also considered to be lack of impact in this organization.

\section{CONCLUSIONS}

We can find that the Social Network Analysis is indeed an efficient method to research the international relationships in recent years. But so far the quantitative study of the ASEAN is still very scared. In the paper, we have used the SNA to explore relationships among the members of the ASEAN based on the economic and trade exchanges. All in all, we finally got two main conclusions:
On the one hand, Indonesia, Singapore, and Malaysia are at the center position of the Association of Southeast Asian Nations, but the importance of Malaysia and Indonesia did not fully reflected as the model is all established on economic data. Meanwhile, the Indonesia has a higher Authority to all the other members. We would do some more researches to explore the reason why the differences were occur in our research.

On the other hand, compared to traditional statistics, the calculations of the Social Network Analysis seems to be more interesting. And the metrics of the SNA are extremely sensitive to the differences of the data in the source graphs. It may cause by the definition of metrics. We would do some more research to consider whether the political influence could give us some more interesting results.

\section{ACKNOWLEDGEMENTS}

Organizational Risk Analyzer (ORA) is a social network analysis program developed by Professor Kathleen M. 
Carley, and this software is distributed by the Center for Computational Analysis of Social and Organizational Systems (CASOS).

\section{REFERENCES}

[1] Yamamoto S. Association of Southeast Asian Nations[J]. The WileyBlackwell Encyclopedia of Globalization.

[2] Nesadurai H. E. S. The Association of Southeast Asian Nations (ASEAN)[J]. New political economy, 2008, 13(2): 225-239.

[3] Ba A. (Re) negotiating East and Southeast Asia: Region, Regionalism, and the Association of Southeast Asian Nations[M]. Stanford University Press, 2009.

[4] Acharya A. The Association of Southeast Asian Nations:" Security Community" or" Defence Community"?[J]. Pacific Affairs, 1991: 159-178.

[5] Lian K. K., Robinson N. A. Regional Environmental Governance: Examining the Association of Southeast Asian Nations (ASEAN) Model[J]. Global Environmental Governance: Options and Opportunities, 2002.

[6] Southeast Asian tribes, minorities, and nations[M]. Princeton, NJ: Princeton University Press, 1967.

[7] Nations A. Association Of Southeast Asian Nations[J]. Thailand economic relations May, 2009, 12: 89 .
[8] Denoon D. B. H., Colbert E. Challenges for the Association of Southeast Asian Nations (ASEAN)[J]. Pacific Affairs, 1998: 505-523.

[9] Maoz Z., " Networks of nations: The evolution, structure, and impact of international networks, 1816-2001," Cambridge University Press, 2010.

[10] Tsvetovat M, Kouznetsov A., "Social Network Analysis for Startups: Finding connections on the social web", O'Reilly Media, Inc., 2011. K. M. Carley, D. Columbus, M. DeReno, J. Reminga and I. Moon, “ ORA User's Guide 2008”, CASOS Technical Report, 2007.

[11] Cao X.,"Networks of Intergovernmental Organizations and Convergence in Domestic Economic Policies," International Studies Quarterly, 2009, vol. 53, no.4, pp.1095-1130.

[12] J. Liu, "An Introduction to Social Network Analysis", Social Science Academic Press (in Chinese), (2004)

[13] J. D. Luo, "Social Network Analysis", Social Sciences Academic Press(China), Second Edition, (in Chinese).

[14] Wasserman S., Faust K., "Social Network Analysis: Methods and Applications", Cambridge university press, 1994.

[15] Scott J. "Social Network Analysis", Sage, 2012.

[16] UN Comtrade Statistics Database, "http://comtrade.un.org/data/", 2015-11-20.

[17] Burt R. S. Structural holes: The social structure of competition[M]. Harvard university press, 2009. 